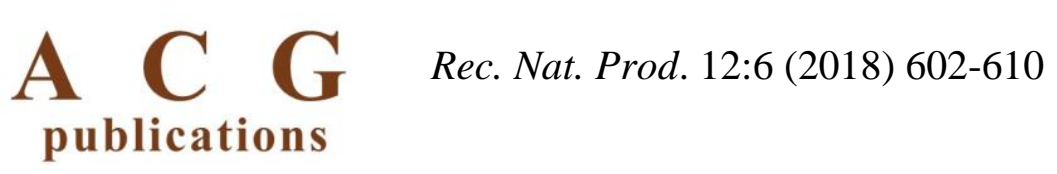

records of natural products

\title{
The Protective Effect and MoA of Panax notoginseng Saponins Combined with Aminoguanidine on Kidney in Diabetic Nephropathy Rats
}

\author{
Guangfu Lv $^{\oplus 1}$, Zhikai Qiu ${ }^{\odot 1}$, Hongbo Ye ${ }^{\odot 1}$, Chao Ma ${ }^{\odot 1}$, Shizhuo Chang ${ }^{\odot 1}$

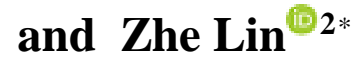

${ }^{1}$ Research and Development Center TCM Pharmacology laboratory, Changchun University of Chinese

\author{
Medicine, Changchun 130117, China \\ ${ }^{2}$ College of Pharmacy, Changchun University of Chinese Medicine 130117, Changchun, China
}

(Received January 08, 2013; Revised February 03, 2018; Accepted February 05, 2018)

\begin{abstract}
This study was conducted to explore the protecting effect and treatment mechanism of Panax notoginseng saponins (PNS) in combination with aminoguanidine (AG) on kidney functions in diabetic nephropathy (DN) rats. Rats were divided into 5 groups (A, P, P+A, D and N) and diabetes was induced by streptozotocin (STZ). After 8 weeks, all rats were sacrificed and the renal functions as well as $24 \mathrm{hrs}$ urinary proteins were examined quantitatively. Periodic acid-Schiff stain (PAS) was used to observe the pathological changes of renal tissue. Immune-nephelometry, immunoradiometric assay, Immunohistochemical and real-time fluorescence were used for blood C-reactive protein, tumor necrosis factor- $\alpha$ (TNF- $\alpha$ ), surface specific marker antigen (ED-1) and determination of transforming growth factor- $\beta 1$ (TGF- $\beta 1$ ) in kidney tissue. There was a significant reduction in renal pathological changes of rats in group $\mathrm{P}, \mathrm{A}$, and $\mathrm{P}+\mathrm{A}$ when compared with group $\mathrm{D}$, while the changes were most obvious in group $\mathrm{P}+\mathrm{A}$. Blood glucose, glomerular volume $(\mathrm{V})$, serum creatinine, 24 hrs urinary protein, blood $\mathrm{CRP}$ and TNF- in groups $\mathrm{P}, \mathrm{A}$ and $\mathrm{P}+\mathrm{A}$ were significantly $(\mathrm{P}<0.05)$ lower than group $\mathrm{D}$ with lowest in group $\mathrm{P}+\mathrm{A}$. Immunohistochemical staining showed, only a few ED-1 positive staining (macrophages) in group $\mathrm{N}$ glomeruli and the renal tubules. The staining of ED-1 group D was higher while in groups $\mathrm{P}, \mathrm{A}$ and $\mathrm{P}+\mathrm{A}$ was significantly reduced. There was a basic quantity of TGF- $\beta 1$ mRNA expression in group $N$ rats while the expression of TGF- $\beta 1 \mathrm{mRNA}$ in group D was significantly increased when compared with control group. In group $\mathrm{P}, \mathrm{A}$ and $\mathrm{P}+\mathrm{A}$, the expression level of TGF- $\beta 1$ mRNA was significantly $(\mathrm{P}<0.05)$ decreased. The protective effect of combined use of these two PNS and AG on the kidney is superior to the single drug treatment. The mechanism of PNS combined with AG in the treatment of DN may be closely related to the reduction of urinary protein, anti-inflammatory response, and inhibition of the expression of TGF- $\beta 1$.
\end{abstract}

Keywords: Diabetic nephropathy; TGF- $\beta 1$; Panax notoginseng .๑ 2018 ACG Publications. All rights reserved.

\section{Introduction}

One of the most common serious micro-vascular complications of diabetes is diabetic nephropathy which is also considered to be one of the most common reasons of end-stage renal disease (ESRD) [1]. The DN has a very complex pathogenesis and has not yet been fully elucidated. Progress in

*Corresponding author: E-Mail: runhua.tian2@gmail.com

The article was published by ACG Publications

www.acgpubs.org/RNP @ November- December/2018 EISSN:1307-6167

DOI: http://doi.org/10.25135/rnp.54.18.01.203 
the prevention and treatment of DN is a subject of common concern in clinical and basic research. In the initiation and development of diabetic nephropathy, inflammatory reaction is involved which is shown by many studies. The infiltration of macrophages is one of the characteristic manifestations of DN. However, the expression of monocyte/macrophage surface specific antigen (ED-1) in DN is increased. Studies have shown that the plasma levels of CRP, TNF- $\alpha$ and other inflammatory factors in patients with DN are significantly higher, and plasma CRP level is a strong predictor of DN. TGF- $\beta 1$ is an important fibrogenic cytokines that plays an increasingly important role in DN [4-5]. One study demonstrated that by antagonizing the inflammatory response, the high glucose-induced TGF- $\beta 1$ expression and the increase of collagen were inhibited and the progression of DN was delayed [6].

Panax notoginseng (PNS) is a traditional medicine of China and has been utilized for nearly 2000 years in China and other oriental countries. PNS is extracted from the plant Panax notoginseng of family araliaceae. It can be used for the treatment of coronary heart disease, coronary arteriosclerotic cardiopathy, cerebrovascular accident, liver function protection, and anti-inflammatory response, as well as anti-fatigue. PNS is a complex extracted from traditional Chinese medicine PNS with various saponins, which has obvious effects of lowering blood viscosity, reducing blood lipids, improving microcirculation and strong antioxidant free radical action [7]. Aminoguanidine (AG) is a selective inhibitor of inducible nitric oxide synthase (iNOS) and a non-enzymatic glycosylation inhibitor, has the effect of retarding the progression of $\mathrm{DN}$ by preventing the formation of advanced glycation end products (AGEs) [8]. At present, there is no report about the effect of PNS combined with AG on inflammatory reaction and pathological damage in diabetic rats. This study was conducted to observe the effects of PNS combined with AG on the pathological changes of kidney in DN rats and its effects on the expression of blood CRP, TNF- $\alpha$ level, TGF- $\beta 1$, and ED-1 in renal tissue of DN rats, as well as its mechanism of improving the renal lesions in $\mathrm{DN}$ rats.

\section{Materials and Methods.}

\subsection{The Reagents and Instruments}

Panax notoginseng saponins (as standards ginsenosides. Their chemical structures/components are provided as supporting information file) was purchased from Yunnan Plant Pharmaceutical Co., Ltd. Aminoguanidine (AG) was purchased from Sigma, USA. CRP kit (the United States BECKMAN company); Immunoradiometric kit of TNF- $\alpha$ (BECKMAN Company, USA); Rabbit anti-rat ED-1 (Beijing Bo Ao Sen Biotechnology Co., Ltd.); HRP-labeled goat anti-rabbit IgG (Beijing, China); Trizol (U.S., BRC); RNA Extraction Kit (QIAGEN); Reverse transcription reagents (Lithuania MBI); Diabetic nephropathy TP (Promega); Coomassie brilliant blue kit (built in Nanjing); A Engine Opticon TM RealTime PCR System (MJ Research Company, USA); Fast blood glucose detector (Johnson \& Johnson). Primer and TaqMan probe sequences: The FAM tagged at the 5 'end of the TaqMan probe is a fluorescent reporter and the TAMRA tagged at the $3^{\prime}$ end is a fluorescent quencher. PCR primers and probes for TGF- $\beta 1$ and GAPDH were synthesized by Shanghai Bioengineering Co., Ltd. Primer and probe sequences are as follows: TGF- $\beta$ 1F: 5'-CCAACTATTGCTTCAGCTCCA-3';TGF- $\beta 1 \mathrm{R}: 5$ 'GTGTCCAGGCTCCAAATGT-3';TGF- $\beta 1 T M$ : 5'-CCAAGGGCTACCATGCCAAC-3; The amplified fragment was $154 \mathrm{bp}$. Internal reference GAPDH F: 5'-TGGGTGTGAAC-CAGGAGAA-3'; GAPDH R: 5'-GGCATGGACT-GTGGTCATGA-3'; GAPDH TM: 5'-ACTGCAC- CACCAACTGCTTAGC-3 '. The amplified fragment was $143 \mathrm{bp}$.

\subsection{Animal Grouping and Model Establishment}

54 clean-grade male SD rats, weighing $180 \pm 25 \mathrm{~g}$, were purchased from Beijing Weitong Lihua Research Laboratory Animal Technology. All rats were fed on clean-grade animals and kept in a ventilated and quiet environment. The rats were free to drink and eat at temperature of $23 \pm 2^{\circ} \mathrm{C}$ and $\mathrm{RH}$ $55 \% \pm 2 \%$. In two groups the rats were divided after 1 week of adaptive feeding, as the normal control group of 10 rats (Group N) and the experimental group of 44 rats, according to the random number table. The 44 rats of experimental group were further divided into DND (Group D), treatment group with PNS (Group P), treatment group with AG (group A) and combined treatment group (group P+A), 10 rats in 
each group while the remaining 4 rats were excluded. $10 \%$ Cholral hydrate $(3 \mathrm{~mL} / \mathrm{kg})$ was used intraperitoneally for anesthesia. Citric acid-trisodium citrate buffer solution $(0.1 \mathrm{~mol} / \mathrm{L} ; \mathrm{pH} 4.5)$ and streptozotocin solution $(\mathrm{STZ}, 65 \mathrm{mg} / \mathrm{kg}$ ) was used for the induction of diabetic in rats by intraperitoneal injection to prepare DN animal model while normal control group (N group) was treated with citrate buffer intraperitoneal injection [9,10]. After 1 week the rats were observed for blood glucose level for three days. The measured blood glucose level was $16.7 \mathrm{mmol} / \mathrm{L}$. After 4 weeks of the successful modeling of the DN rat model, the urine albumin excretion rate (UAER) of D,P,A and P+A groups were measured with $24 \mathrm{hrs}$ urine volume, and the results were statistically analyzed. The UAER for the experimental and normal control group rats were tested by t-test. A p-value less than $0.05(\mathrm{P}<0.05)$ was considered to be statistically significant. The statistical results for UAER are shown in Table 1.

Table 1. Expression of UAER in rats after 4 weeks of modeling* (mg/24hrs, $\overline{\boldsymbol{x}} \pm \boldsymbol{s} \mathrm{n}=10)$

\begin{tabular}{llllll}
\hline Groups & Group N & Group D & Group P & Group A & Group P+A \\
\hline UAER & $4.42 \pm 0.54$ & $219.35 \pm 7.2^{*}$ & $223.52 \pm 8.6^{*}$ & $228.46 \pm 9.4^{*}$ & $231.45 \pm 9.5^{*}$ \\
\hline
\end{tabular}

*Compared with the control group, $* \mathrm{P}<0.05$.

\subsection{Method of Administration}

DN rats were treated with a balanced feeding for 3 days after successful modeling of the DN rats. The group P was given PNS with $100 \mathrm{mg} \mathrm{kg}-1 \mathrm{~d}-1$ for gavages, while the group A was given AG with $100 \mathrm{mg}$ kg-1 d-1. Similarly the group P+A was given AG 100 milligram kg-1 d-1 and PNS $100 \mathrm{mg} \mathrm{kg-1}$ d-1 for gavages. The treatment was continued for 8 weeks. Group $\mathrm{N}$ and group D were given equal volume of normal saline. During the experiment, all rats were kept in cage, fed freely without insulin and other hypoglycemic drugs. At the end of the experiment, no rat was died in any group.

\subsection{Detection Index and Determination Method}

After eight weeks of treatment, blood glucose was measured and 24 hrs urine was collected by metabolic cage for urine protein detection. Blood was taken from the abdominal aorta and used for the determination of serum creatinine (Scr), CRP and TNF- $\alpha$ [11]. All specimens were collected and tested in one time. After blood sample collection, rats were sacrificed. The bilateral kidneys were excised and partial kidneys were fixed with $4 \%$ paraformaldehyde, implanted in paraffin and sectioned for histopathological PAS staining and immunohistochemistry. In partial kidneys, the renal tissue RNA was extracted by Trizol, and real time fluorescence quantitative PCR was used for the detection of expression level of TGF $\beta 1 \mathrm{mRNA}$ after reverse transcription. Some renal tissues were homogenized to extract the supernatant, and ELISA was used for the detection of TGF- $\beta 1$ protein level.

\subsubsection{PAS Staining}

PAS staining was performed according to the conventional method. The pathological changes of renal tissue were observed under the electron microscope and the Image Proplus5.0 multimedia color pathological image analysis software was used to analyze the pathological changes. A double blind method was used to evaluate the pathological changes of renal tissue and to calculate the glomerular volume (V). PAS-stained sections were taken and 10 glomeruli were collected randomly from each rat at a magnification of 400 times of the microscope. The mean glomerular area (A) was measured and the value of $\mathrm{V}$ was calculated. The formula is: $\mathrm{V}=\beta / \mathrm{K} \times \mathrm{A} 3 / 2 \beta=1.38$ (morphological coefficient, $\mathrm{K}=1.1$ ) (the coefficient of size distribution)

\subsubsection{Quantitation of Blood Glucose, Serum Creatinine and 24 hrs Urinary Protein}

Blood glucose was measured by a fast blood glucose detector. Backman automatic biochemical analyser was used for the determination of serum creatinine level. The quantitative determination of 24 hrs urinary protein was detected by Coomassie brilliant blue method [11]. 


\subsubsection{Detection of Inflammatory Reaction Factors}

The level of blood C-reactive protein (CRP) was detected by immune nephelometry, and the tumor necrosis factor- $\alpha$ (TNF- $\alpha$ ) level in blood were detected by using immunoradiometric assay.

\subsubsection{The Expression of ED-1 in Renal Tissue by Immunohistochemical Staining}

The SP method was used for immunohistochemical staining, and the specific operation was carried out according to the instructions. Image Pro plus5.0 multimedia color pathological image analysis software was used to analyze the results. The IOD value of the positive region was calculated, and the average value was compared (Under the 400 times mirror, each rat was randomly selected to collect 20 fields of vision.). The greater the IOD value, the higher the level of antigen expression, and vice versa.

\subsubsection{The TGF- $\beta 1 m R N A$ Level Determination}

After determining the tissue RNA concentration, extracted by Trizol method with ultraviolet spectrophotometer, $2 \mu \mathrm{g}$ total RNA was used for reverse transcriptase reaction [11]. Polymerase chain reaction (PCR) amplification was performed using a diabetic nephropathy A Engine OpticonTM real-time fluorescence quantitative PCR instrument in a $30 \mu \mathrm{l}$ reaction system. Amplification conditions for predegeneration was 2 minutes at temperature of $94^{\circ} \mathrm{C}, 30$ seconds for denaturation at temperature of 94 ${ }^{\circ} \mathrm{C}, \quad 30$ seconds for annealing at temperature of $60{ }^{\circ} \mathrm{C}$, and 30 seconds for extension at temperature of 72 ${ }^{\circ} \mathrm{C}$ for 40 cycles, recording the Cyclethreshold values for each specimen and reference. The relative quantitative analysis of real time fluorescence quantitative PCR $(2-\Delta \Delta \mathrm{CT})$ was used for statistical analysis. 2- $\Delta \Delta \mathrm{CT}$ indicates the relative value of the copy number of mRNA expression of the target genes in the experimental group.

\subsection{Statistical Analysis}

The SPSS version 21 was used for the processing of experimental data as statistical tool and expressed as $\bar{x} \pm s$, while $t$ test was used for the comparison of two groups. For the comparison between multiple groups and multiple time points in the same group, the One-Way ANOVA analysis was used to identify the homogeneity of variance. The LSD method was used in the comparison between pairwise groups, and Tamhane analysis was used for the heterogeneity of variance. $\mathrm{P}<0.05$ means the difference was statistically significant.

\subsection{Ethical Consideration}

This study was approved by the Institutional ethical committee of Changchun University of Chinese Medicine, Changchun 130117, China. The Reference No. is JAN152017/P.

\section{Results and Discussion}

\subsection{Comparison of the General Situation}

When group $\mathrm{N}$ was compared with group $\mathrm{D}$, the obvious symptoms of the Group D rats were apathetic, dull coat, unresponsive, bow dorsiflexion, polydipsia, polyuria, polyphagia, emaciation and so on. One rat developed diarrhea. The above situations of group P, group A and group P+A were obviously improved. 


\subsection{Comparison of Pathological Changes}

The results of PAS staining showed that, In group $\mathrm{N}$, the shape of glomeruli was regular, the basement membrane was thin, the inner mesangial cells were few and sparsely, the renal tubule structure was clear, and the basement membrane of the renal tubule was not changed. The number of glomerulus in group $\mathrm{D}$, group $\mathrm{P}$, group $\mathrm{A}$ and group $\mathrm{P}+\mathrm{A}$ was significantly increased. The mesangial matrix hyperplasia, basement membrane thickening and PAS staining positive substance increased obviously, but the tubular change was insignificant. The pathological changes of kidney were improved in group P, group A, group P+A and group D. Statistical results of glomerular volume showed that, compared with group $\mathrm{N}$, the $\mathrm{V}$ value of group $\mathrm{D}$ increased as $\mathrm{p}$-value was less than 0.05 , and the $\mathrm{V}$ value of group $\mathrm{P}$, group $\mathrm{A}$ and group $\mathrm{P}+\mathrm{A}$ all decreased significantly, when comparison was done with group $\mathrm{D}$, and the $\mathrm{V}$ value in group P+A was significantly lower than that in group A and group P as shown in Figures 1 and 2.
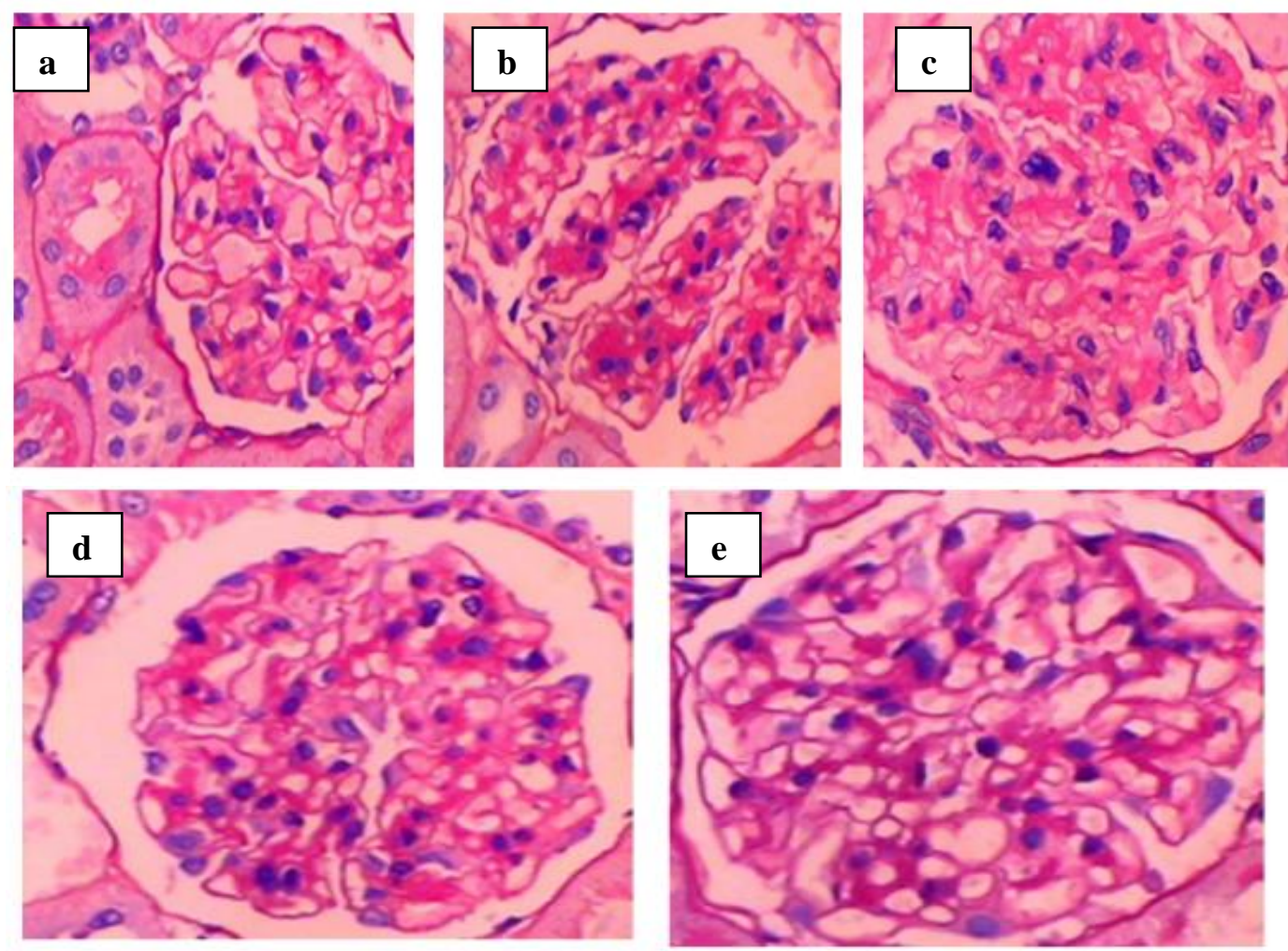

Figure 1. Pathological changes of kidney in rats of each group (PAS staining, X200)
(a) $\mathrm{N}$ group (b) $\mathrm{D}$ group
(c) $\mathrm{P}$ group
(d) A group
(e) $\mathrm{P}+\mathrm{A}$ group

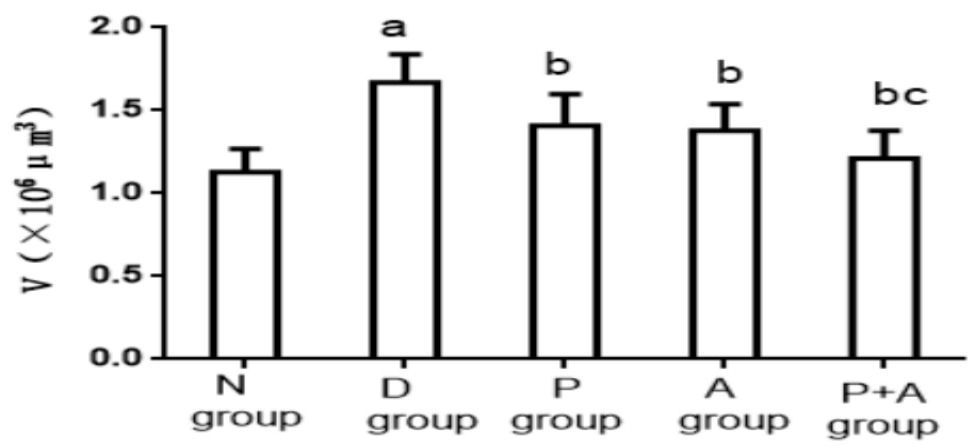

Figure 2. Comparison of V values in 5 groups' rats*

* compared with the group $\mathrm{N}$, ${ }^{\mathrm{a}} \mathrm{P}<0.05$; compared with the group $\mathrm{D},{ }^{\mathrm{b}} \mathrm{P}<0.05$; compared with the group $\mathrm{P}$ and group $\mathrm{A},{ }^{\mathrm{c}} \mathrm{P}<0.05$. 


\subsection{Comparison of Blood Glucose, Serum Creatinine and 24 hrs Urinary Proteins}

In group D, the blood glucose level was maintained at a high level, serum creatinine and $24 \mathrm{hrs}$ urinary protein levels were significantly $(\mathrm{P}<0.05)$ higher than group $\mathrm{N}$. The levels of blood glucose, serum creatinine and $24 \mathrm{hrs}$ urinary protein in group $\mathrm{P}$, group $\mathrm{A}$ and group $\mathrm{P}+\mathrm{A}$ were all significantly $(\mathrm{P}<0.05)$ lower than group $\mathrm{D}$ and the levels of blood glucose, serum creatinine and urinary protein in group $\mathrm{P}+\mathrm{A}$ were significantly lower than group $\mathrm{P}$ and group $\mathrm{A}$, as depicted in Table 2.

Table 2. Comparison of blood glucose, serum creatinine and 24 hrs urinary proteins in rats of 5 groups* $\underline{(\mathrm{n}=10)}$

\begin{tabular}{llcccccc}
\hline Groups & Group N & Group D & Group P & Group A & Group P+A & F & P \\
\hline $\begin{array}{l}\text { Blood glucose } \\
\text { (mmol/L) }\end{array}$ & $5.07 \pm 0.4$ & $27.11 \pm 0.43^{\mathrm{a}}$ & $13.49 \pm 1.54^{\mathrm{b}}$ & $12.55 \pm 3.52^{\mathrm{b}}$ & $7.09 \pm 46.80^{\mathrm{bc}}$ & 20.57 & $<0.01$ \\
$\begin{array}{l}\text { Serum creatinine } \\
(\mu \mathrm{mol} / \mathrm{L})\end{array}$ & $54.7 \pm 4.3$ & $89.67 \pm 2.25^{\mathrm{a}}$ & $65.16 \pm 4.78^{\mathrm{b}}$ & $64.13 \pm 4.42^{\mathrm{b}}$ & $56.07 \pm 3.05^{\mathrm{b}}$ & 22.12 & $<0.01$ \\
$\begin{array}{l}24 \mathrm{hrs} \mathrm{urinary} \text { protein } \\
(\mathrm{mg} / 24 \mathrm{hrs})\end{array}$ & $147.3 \pm 29.2$ & $915.46 \pm 47.34^{\mathrm{a}}$ & $424.71 \pm 35.56^{\mathrm{b}}$ & $422.16 \pm 34.27^{\mathrm{b}}$ & $223.57 \pm 24.12^{\mathrm{bc}}$ & 24.96 & $<0.01$ \\
\hline
\end{tabular}

*Compared with the group $\mathrm{N}$, ${ }^{\text {a }}<0.05$; compared with the group $\mathrm{D},{ }^{\mathrm{b}} \mathrm{P}<0.05$; compared with the group $\mathrm{P}$ and group $\mathrm{A},{ }^{\mathrm{c}} \mathrm{P}<0.05$.
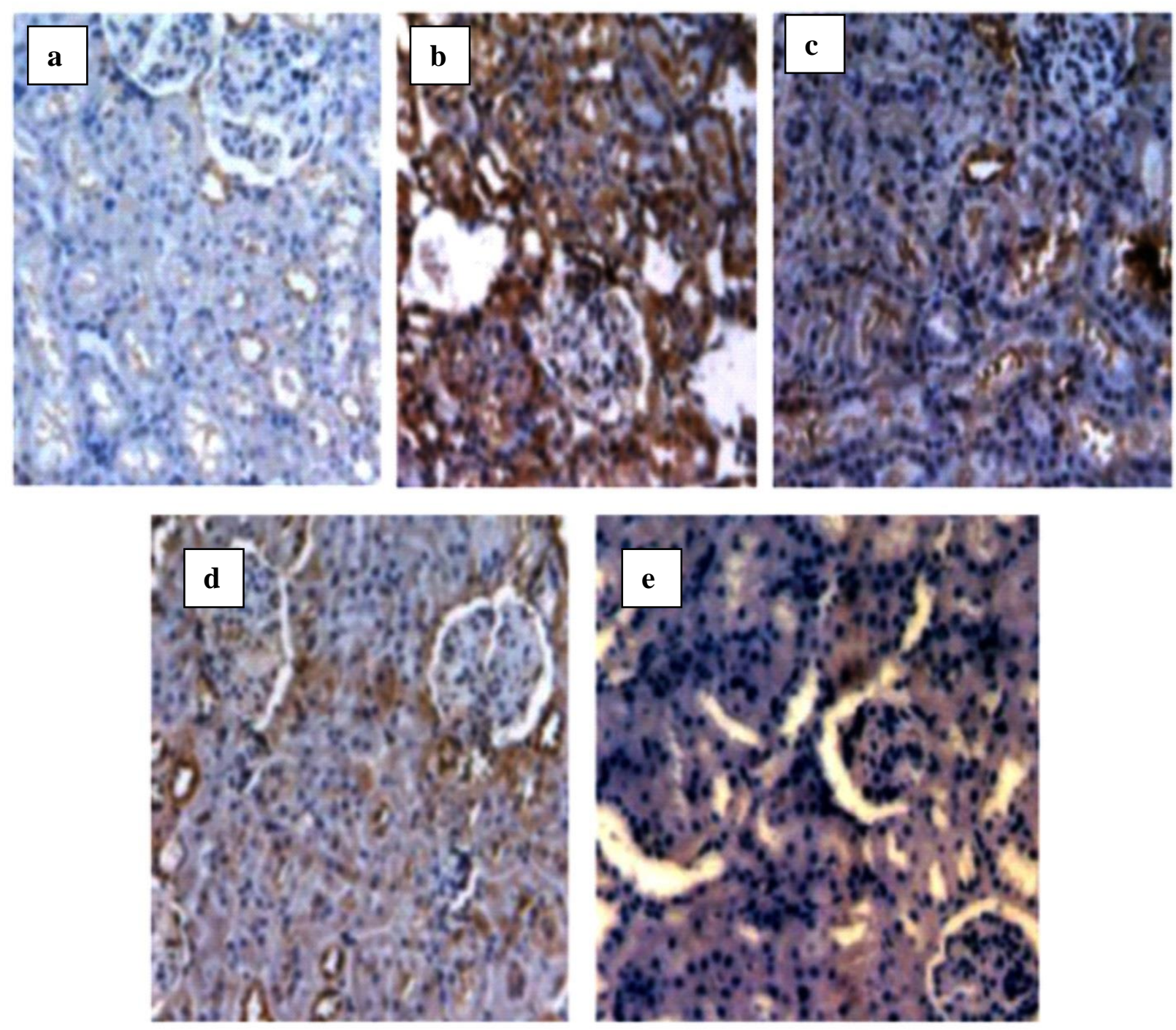

Figure 3. Expression of ED-1 in kidney tissue of rats in each group (immunohistochemical staining, $X 200$ )
(a) $\mathrm{N}$ group
(b) D group
(c) $\mathrm{P}$ group
(d) A group
(e) $\mathrm{P}+\mathrm{A}$ group 


\subsection{Comparison of Inflammatory Reaction}

The levels of blood CRP and TNF- $\alpha$ in the rats of D group was elevated than the group-N rats with the significant difference of p-value less than 0.05. Group P, A and P+A were all improved when compared with group D. Immunohistochemical staining showed, in the rats of group N, only a few ED-1 positive staining (macrophages) were expressed in the glomeruli, around the glomeruli, in the renal tubules and in the interstitium. The staining of ED-1 positive cells in the above parts of group D was significantly elevated than that in group $\mathrm{N}$ as $\mathrm{p}$-value was less than 0.05 . Similarly the staining of positive cells of ED-1 in group P, A and P+A were significantly declined, and the staining degree of ED-1 positive cells in group $\mathrm{P}+\mathrm{A}$ was the lowest as shown in Figure 3 and Table 3.

Table 3. Comparison of inflammatory reaction in rats in 5 groups* $(\overline{\boldsymbol{x}} \pm s, \mathrm{n}=10)$

\begin{tabular}{llllllll}
\hline Groups & Group N & Group D & Group P & Group A & Group P+A & F & P \\
\hline CRP $(\mathrm{mg} / \mathrm{L})$ & $4.41 \pm 0.41$ & $16.92 \pm 0.92^{\mathrm{a}}$ & $13.49 \pm 1.54^{\mathrm{b}}$ & $8.16 \pm 1.11^{\mathrm{b}}$ & $7.09 \pm 46.80^{\mathrm{bc}}$ & 20.57 & $<0.01$ \\
TNF- $\alpha(\mu \mathrm{g} / \mathrm{L})$ & $1.07 \pm 0.09$ & $2.80 \pm 0.56^{\mathrm{a}}$ & $1.33 \pm 0.16^{\mathrm{b}}$ & $1.24 \pm 0.16^{\mathrm{b}}$ & $56.07 \pm 3.05^{\mathrm{b}}$ & 22.12 & $<0.01$ \\
ED-1 $(\mathrm{IOD})$ & $1.12 \pm 0.16$ & $3.98 \pm 0.21^{\mathrm{a}}$ & $424.71 \pm 35.56^{\mathrm{b}}$ & $1.74 \pm 0.81^{\mathrm{b}}$ & $1.68 \pm 0.74^{\mathrm{bc}}$ & 24.96 & $<0.01$ \\
\hline
\end{tabular}

$*$ Compared with the group $\mathrm{N}$, ${ }^{\mathrm{a}} \mathrm{P}<0.05$; compared with the group $\mathrm{D},{ }^{\mathrm{b}} \mathrm{P}<0.05$; compared with the group $\mathrm{P}$ and group $\mathrm{A},{ }^{\mathrm{c}} \mathrm{P}<0.05$.

\subsection{The Effect of TGF- $\beta 1$ mRNA Expression in Kidney Tissues}

There was a normal basic amount of TGF- $\beta 1$ mRNA expression in the kidney tissues of the group $\mathrm{N}$ rats, and the expression of TGF- $\beta 1$ mRNA in group $\mathrm{D}$ was significantly increased when compared with control group, and there was a significant difference. The expression level of TGF- $\beta 1$ mRNA in group P, group $\mathrm{A}$ and group $\mathrm{P}+\mathrm{A}$ was significantly declined when compared with group $\mathrm{D}$ as p-value was less than 0.05 and the expression level of TGF- $\beta 1$ mRNA in group $\mathrm{P}+\mathrm{A}$ was significantly lower than group $\mathrm{P}$ and group A.

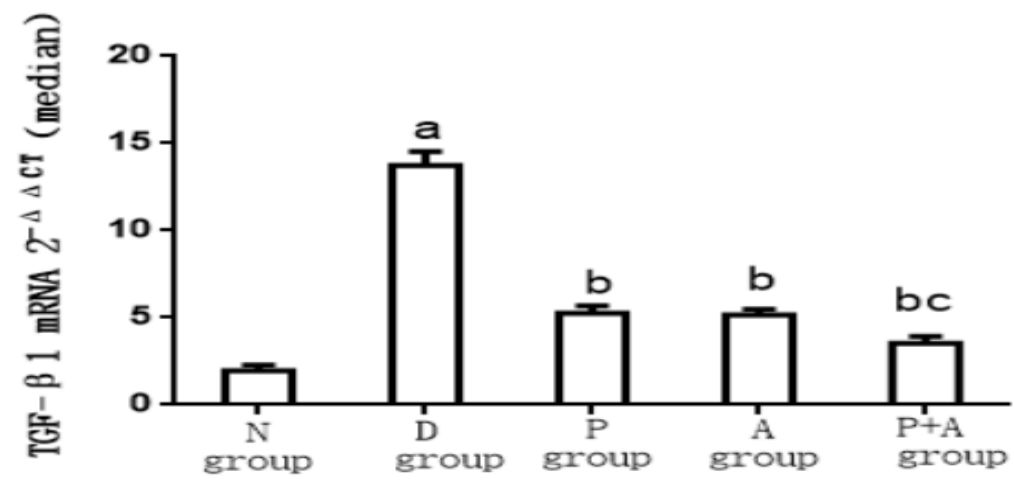

Figure 4. Effect of TGF- $\beta 1$ mRNA expression in kidney tissues of rats*

*Compared with the group $\mathrm{N},{ }^{\text {a }} \mathrm{P}<0.05$; compared with the group $\mathrm{D},{ }^{\mathrm{b}} \mathrm{P}<0.05$; compared with the group $\mathrm{P}$ and group $\mathrm{A},{ }^{\mathrm{c}} \mathrm{P}<0.05$.

STZ is a broad-spectrum antibiotic, which can specifically destroy islet $\beta$ cells, resulting in reduced insulin secretion and elevated blood glucose. Our study confirmed that STZ solution $(65 \mathrm{mg} / \mathrm{kg})$ a one-time intraperitoneal injection of 1 week showed significant elevated blood glucose in rats. After 8 weeks of administration, 24 hrs urinary protein and creatinine level increased, mesenchyme matrix increased significantly, PAS staining positive substance increased, interstitial lymphocytes and monocyte infiltration increased, as well as a series of diabetic nephropathy symptoms. The results showed that our animal model of DN was successful.

Panax notoginseng saponins (Figure 5) are the main active ingredients of Panax notoginseng. The results of this study show that the PNS combined with AG can obviously improve the pathological 
damage of diabetic nephropathy caused by STZ, and the quantitation of 24 hrs urinary protein and the decrease of serum creatinine. This may be one of the mechanisms of treatment with the PNS combined with AG treatment on kidney damage in DN rats.

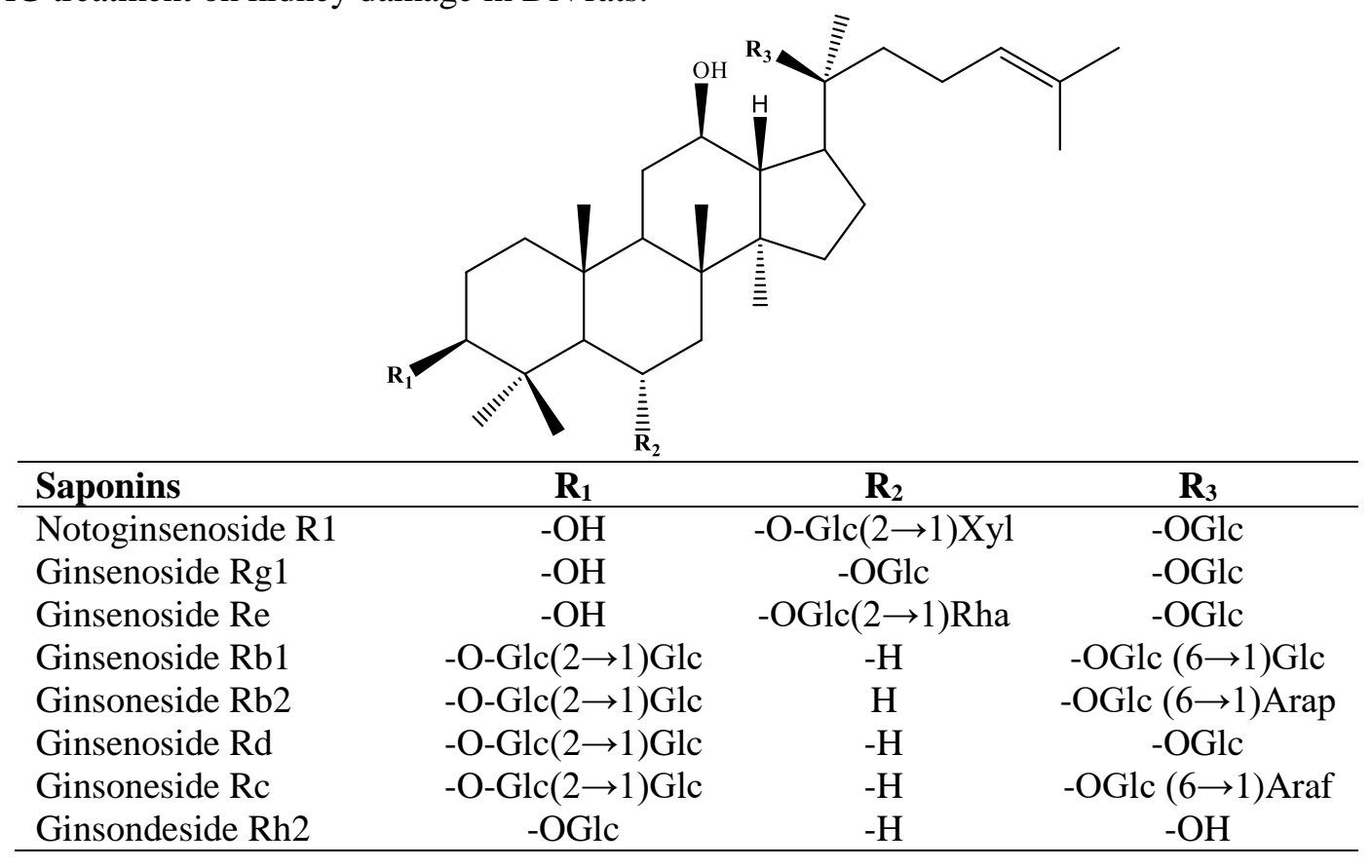

Figure 5. The main saponins in the extract of Panax notoginseng

TGF- $\beta 1$ is an important fibrogenic factor that plays an important role in the development of DN. We found that the TGF- $\beta 1$ gene levels of model group were significantly higher. Compared with group $\mathrm{D}$, the expression of TGF- $\beta 1 \mathrm{mRNA}$ in group P, group A and group P + A was significantly decreased and the expression of TGF- $\beta 1$ mRNA in group $\mathrm{P}+\mathrm{A}$ was significantly lower than that in the group $\mathrm{P}$ and group A.

DN is a common complication of diabetes and one of the main causes of diabetes. So far, its pathogenesis has not been fully understood. At present, the theory of inflammation has attracted much attention. Many experimental and clinical data suggest that inflammatory cell infiltration, cytokines and inflammatory mediators increase in DN [12-13]. A key role might be played by inflammation in the diabetic renal pathogenesis injury alone [14-16]. The results of this experiment also confirmed that the levels of ED-1, CRP and TNF- $\alpha$ in renal tissue increased in DN rats, indicating that there was a significant inflammatory reaction process in diabetic nephropathy. CRP, TNF- $\alpha$ and other inflammatory factors may lead to renal fibrosis and pathological damage by activating the important fibrogenic cytokine TGF- $\beta 1$. After the treatment of PNS combined with AG, the levels of ED-1, CRP and TNF- $\alpha$ in renal tissue were all improved in DN. The treatment with PNS combined with AG can counteract the inflammatory reaction of DN and inhibit the increase of inflammatory cytokines CRP and TNF- $\alpha$, which may also be one of the mechanisms of PNS combined with AG in protecting kidney from DN.

As a conclusion, both PNS and AG can improve the pathological damage of kidney in DN rats by reducing the level of TGF- $\beta 1$ and inflammatory reaction factors. The protective effect of combined use of these two groups on the kidney is superior to the single drug treatment. The mechanism of treatment with PNS combined with AG on kidney in DN may be related to the reduction of urinary protein, antiinflammation, inhibition of TGF- $\beta 1$ expression and other factors.

\section{ORCID}

Guangfu Lv: 0000-0002-8307-726X

Zhikai Qiu: 0000-0002-6163-0634

Hongbo Ye: 0000-0003-3180-1188

Chao Ma: 0000-0003-2043-9996

Shizhuo Chang: 0000-0003-3434-4621 
Zhe Lin: $\underline{0000-0002-7292-2173}$

\section{References}

[1] J. Wada and H. Makino (2016). Innate immunity in diabetes and diabetic nephropathy, Nature. Rev. Nephrol. 12, 13-26.

[2] A. Lewis, R. Steadman and P. Manley (2008). Diabetic nephropathy, inflammation, hyaluronan and interstitial fibrosis, Histol. Histopathol. 23, 731-739.

[3] B. Cui, J.H. Sun, and F.F. Xiang (2012). Aquaporin 4 knockdown exacerbates streptozotocin-induced diabetic retinopathy through aggravating inflammatory response, J. Exp. Eye. Res. 98, 37-43.

[4] W. Qi, J. Mu and Z.F. Luo (2011). Attenuation of diabetic nephropathy in diabetes rats induced by streptozotocin by regulating the endoplasmic reticulum stress inflammatory response, J. Met-clin. Exp. 60, 594-603.

[5] K.H. Chan, K. Brennan, and N.C. You (2011). Common variations in the genes coding for C-Reactive Protein (CRP), Tumor Necrosis Factor Alpha (TNF- $\alpha$ ), and Interleukin-6 (IL-6) and risk of clinical diabetes in the women's health initiative observational study, J. Clin. Chem. 57, 317-325.

[6] X. Wang, S. Shaw, and F. Amiri (2002). Inhibition of the Jak/STAT signaling pathway prevents the high glucose-induced increase in tgf-beta and fibronectin synthesis in mesangial cells, J. Diabet. 51, 3505-3509.

[7] W. Nan, J.B. Wan, and S.W. Chan (2011). Comparative study on saponin fractions from Panax notoginseng, inhibiting inflammation-induced endothelial adhesion molecule expression and monocyte adhesion, J. Chin. Med. 6, 37-48

[8] F.A. Reza, S.M. Razavi and P.A. Nejad (2011). The use of aminoguanidine, a selective inducible nitric oxide synthase inhibitor, to evaluate the role of nitric oxide on periapical healing, Dent. Res. J. 8, 197202.

[9] R. Meiyu and W. Xinyi (2010). Evaluation of three different methods to establish animal models of Acanthamoeba keratitis, Yonsei. Med. J. 51, 121-127.

[10] E.P.K. Mensahbrown, E.N. Obineche, S. Galadari, E. Chandranath, A. Shahine, I. Ahmed, S.M. Patel, and A. Adem (2011). Streptozotocin-induced diabetic nephropathy in rats: The role of inflammatory cytokines, J. Cyt. 31, 180-190.

[11] Z. Shuhong, L. Hongjun, C. Bo, L. Xu, and S. Bingyin (2013). The effect of Dantonic Pill on $\beta$-Catenin expression in a rat model of Streptozotocin-induced early stage of diabetic nephropathy, J. Diabet. Res. doi: $10.1155 / 848679$

[12] D.L. Chong, A.R. Folsom, and F.J. Nieto (2001). White blood cell count and incidence of coronary heart disease and ischemic stroke and mortality from cardiovascular disease in African-American and white men and women: Atherosclerosis risk in communities study, Amer. J. Epidemiol. 154, 758-764.

[13] M. Kumar, K. Roe, and P.V. Nerurkar (2014). Reduced immune cell infiltration and increased proinflammatory mediators in the brain of Type 2 diabetic mouse model infected with West Nile virus, $J$. Neuinflamm. 11, 80-87.

[14] D.L.G. Pérez, H. Maier and E. Nieto (2001). Chemokine expression precedes inflammatory cell infiltration and chemokine receptor and cytokine expression during the initiation of murine lupus nephritis, J. Amer. Soc. Nephrol. 12, 1369-1382.

[15] S. Bengmark (2008). Amplifiers of systemic inflammation-The role advanced glycation and lipoxidation end products in foods, J. Kuw. Med. Assoc. 40, 3-17.

[16] L. Azadbakht, S. Atabak, and A. Esmaillzadeh (2008). Soy protein intake, cardiorenal indices, and Creactive protein in type 2 diabetes with nephropathy: a longitudinal randomized clinical trial, J. Diabet. Care. 31, 648-654.

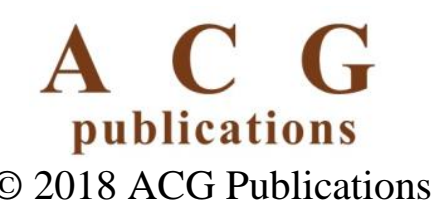

